\title{
Стероидозависимая бронхиальная астма: рекомендации по ведению пациентов и снижению дозы системных глюкокортикостероидов
}

1 - ФГУН "Казанский научно-исследовательский институт эпидемиологии и микробиологии" Роспотребонадзора: 420015, Респуболика Татарстан, Казань, ул. Б. Красная, 67

2 - ГОУ ДПО "Казанская государственная медицинская академия" Росздрава, кафедра аллергологии и иммунологии: 420012, Республика Татарстан, Казань, ул. Муштари, 11

\section{R.S.Fassakhov, I.D.Reshetnikova}

\section{Steroid-dependent bronchial asthma: recommendations on management of the patients and reduction in dosage of systemic steroids}

\begin{abstract}
Key words: steroid-dependent bronchial asthma, oral steroids, long-acting beta2-agonists, inhaled steroids.
Ключевые слова: стероидзависимая бронхиальная астма, пероральные стероиды, длительно действующие $\beta_{2}$-агонисты, ингаляционные стероиды.
\end{abstract}

Стероидозависимая бронхиальная астма (БА) продолжает оставаться серьезной медицинской проблемой в связи с упорным, постоянно рецидивирующим неконтролируемым течением. Для предупреждения ее симптомов больной вынужден длительными (в течение месяцев) курсами или на постоянной основе принимать системные глюкокортикостероиды (сГКС) в виде таблеток или инъекций. Это неизбежно сопровождается развитием многообразных побочных эффектов, причем неблагоприятное влияние стероидов зачастую выходит на первый план, преобладая даже над симптомами заболевания. Статистические данные свидетельствуют о том, что сГКС на постоянной основе принимают от 10 до $48 \%$ больных БА. Однако до сих пор в международных и отечественных руководствах по диагностике и лечению бронхиальной астмы отсутствуют практические рекомендации по ведению таких пациентов и, что особенно важно с практической точки зрения, по снижению дозы и отмене сГКС у этой категории больных [1].

В связи с этим разработка эффективных и безопасных подходов к снижению дозы и отмене сГКС у больных стероидозависимой БА является актуальной проблемой. Чтобы не допустить зависимости больного от сГКС или отменить прием этих препаратов ведение пациентов должно включать в себя ряд этапов (таблица).

Первый этап. Проведенный нами анализ позволил выявить нижеследующие причины стероидозависимости (рассмотрим их в порядке значимости):

1. Ошибочная диагностика стероидозависимой БА.

У взрослых проводят дифференциальную диагностику с ХОБЛ, дисфункцией голосовых связок, синдромом Чарджа-Стросс, астматическим вариан- том узелкового периартериита, опухолями бронхов, бронхоэктазами, реже - с трахеобронхомаляцией, обструктивным бронхиолитом. $[1,2]$. У детей к этим диагнозам следует добавить муковисцидоз, врожденные аномалии верхних дыхательных путей, дисфункцию ресничек и аспирацию инородных тел [3].

И если при синдроме Чарджа-Стросс и узелковом периартериите применение сГКС по ежедневной схеме вполне обосновано, то назначение их больным с ХОБЛ, патологией голосовых связок, трахеобронхомаляцией - не показано.

Ошибки в этиологической диагностике БА. Консультация аллерголога обязательна для всех больным с диагнозом БА, оптимально - при первичной постановке диагноза. Неверным является распространенное мнение о том, что больные, постоянно принимающие сГКС, не нуждаются в консультации аллерголога. Только аллерголог сможет квалифицированно подтвердить (или исключить) аллергическую природу заболевания. По последним данным, от 40 до $67 \%$ взрослых больных БА страдают аллергической формой заболевания [4, 5]. При этом у 50-93,5 \% пациентов с тяжелой БА выявляют сенсибилизацию к нескольким ингаляционным аллергенам [6, 7]. Анализ этиологического диагноза БА, проведенный в поликлиниках Казани показал, что атопическая форма зафиксирована в среднем у $15 \%$ из стоящих на учете взрослых больных БА, т. е. у 35-40 \% всех больных БА этиологический диагноз - ошибочный.

Вторая по частоте ошибка связана с "аспириновой" астмой, которая диагностируется среди стероидозависимых больных БА в $\geq 19 \%$ случаев. Манифестированную или субклиническую форму непереносимо- 
1-й этап. Дифференциальная диагностика стероидозависимой БА. Выявление и устранение причин стероидной зависимости

1. Во избежание ошибочной диагностики стероидозависимой БА необходимо исключить у взрослых

ХОБЛ;

астматический вариант узелкового периартериита; опухоли бронхов;

синдром Черджа-Стросс;

бронхоэктазы; дисфункцию голосовых связок;

трахебронхомаляцию; обструктивный бронхиолит

у детей

муковисцидоз;

врожденные аномалии верхних дыхательных путей; дисфункцию ресничек; аспирацию инородных тел

Ошибки в этиологической диагностике и обусловленные ими ошибки в лечении

Атопия $\Rightarrow$ элиминационный режим

Аспириновая триада $\Rightarrow$ отмена НПВС

Гастроэзофагеальный рефлюкс;

непереносимость НПВС;

тиреотоксикоз;

аллергический бронхолегочной аспергиллез;

хронический гнойный или грибковый риносинусит;

нарушение продукции женских половых гормонов

3. Неадекватная фармакотерапия

Позднее назначение иГКС (только при неэффективности других методов терапии);

необоснованное назначение пролонгированных сГКС

неправильные схемы лечения ГКС

4. Крайне тяжелое нестабильное течение БА, не поддающееся другим методам лечения

5. Другие причины

Недоверие к ингаляторам

привычка к таблеткам;

стоимость базисной терапии

2-й этап. Замещение сГКС комбинацией иГКС и пролонгированных ингаляционных $\beta_{2}$-адреномиметиков

3-й этап. Через 2-4 нед. после начала 2-го этапа - снижение дозы сГКС

4-й этап. Подбор оптимальной дозы базисной терапии

Примечание: ХОБЛ - хроническая обструктивная болезнь легких; НПВС - нестероидные противовоспалительные средства; иГКС - ингаляционные глюкокортикостероиды.

сти НПВС выявляют у 80 \% больных с полипозным риносинуситом $[8,9]$. В среднем по Российской Федерации интерполированный показатель обращаемости по поводу полипозного риносинусита составляет 4,9 на 10 тыс. населения [10]. Прием НПВС может рассматриваться как фактор риска формирования стероидорезистентности, обусловливающий отсутствие у больных контроля над БА [11].

Ошибки в этиологической диагностике и исходящие из них ошибки в лечении. Ошибки в диагностике ведут к неадекватной терапии заболевания. Первым и важнейшим этапом в лечении данной категории больных является проведение комплекса элиминационных мероприятий по снижению и, если возможно, полному устранению контакта с причинно-значимым аллергеном (уровень доказательности А) [12]. Одних этих мероприятий (при аллергии на домашнюю пыль - удаление "пылесборников", обработка акарицидными средствами и использование гипоаллергенного постельного белья), как правило, бывает достаточно для существенного улучшения течения заболевания и, следовательно, уменьшения дозы принимаемых противовоспалительных и симптоматических препаратов.

И напротив, невыполнение этих мероприятий приводит к тяжелому течению заболевания, вплоть до стероидозависимости. Растет количество публикаций о тяжелом течении БА у больных с аллергией на споры плесневых грибов, аллергены тараканов.
Серьезную проблему представляет аллергия на домашних животных, поскольку все чаще встречается сенсибилизация к аллергенам кошек и собак. Существуют и объективные причины, затрудняющие специфическую диагностику. Так, в России не выпускаются и не зарегистрированы аллергены тараканов и плесневых грибов, отечественные аллергены из шерсти домашних животных (кошка, собака) выявляют сенсибилизацию лишь у 45 \% больных.

Несвоевременное проведение аллергологической диагностики и, как следствие, невыполнение элиминационных мероприятий являются, по нашим наблюдениям, причиной применения сГКС у каждого 4-го больного со стероидозависимой БА.

2. Сопутствующие заболевания, утяэкеляющие течение БА и способствующие стероидной зависимости.

Одной из причин тяжелого неконтролируемого течения БА может быть сопутствующее заболевание: хронический гнойный или грибковый синусит, аллергический бронхолегочный аспергиллез, тиреотоксикоз, гастроэзофагеальная рефлюксная болезнь. Терапия сопутствующего заболевания при адекватной базисной терапии БА позволяет отменить или существенно уменьшить дозу сГКС [11, 13-15].

3. Неадекватная фармакотерапия БА.

С одной стороны, речь идет о позднем назначении иГКС "только при неэффективности других методов лечения" больным персистирующей БА, что приводит к прогрессированию воспаления и утяже- 
лению течения заболевания, с другой стороны - об увлечении сГКС и назначении неправильных режимов дозирования пациентам с тяжелой БА. С сожалением приходится констатировать, что до сих пор больным БА назначают депо-препараты - триамцинолона (Кеналог-40), метилпреднизолона (Метипред-40, Депо-медрол) и бетаметазона (Дипроспан). В качестве оправдания такого метода терапии указывается его "удобство для больных": 1 инъекция улучшает состояние пациента на 3-4 нед. При этом не учитывают то, что депонированные препараты ГКС представляют наибольшую опасность в плане развития побочных эффектов, прежде всего стероидозависимости. Создаваемая при их применении постоянная концентрация ГКС в крови через 4-5 инъекций приводит к угнетению коры надпочечников, часто необратимому - больные уже не смогут обходиться без введения этих препаратов. Наряду с развитием стероидного васкулита, диабета, миопатии, исподволь формируется одно из наиболее неблагоприятных осложнений - остепороз, возрастает риск переломов. У больных с тяжелой стероидозависимой БА высок риск осложнений оперативного лечения переломов, обусловленный плохим заживлением ран, стероидным диабетом. Именно с этими обстоятельствами связаны катастрофические цифры: летальность в течение 1-го года после перелома проксимального отдела бедренной кости при остеопорозе достигает 30-35 \%, а из числа выживших пациентов в постоянном уходе нуждаются 78 \% спустя 1 год после перелома и $65 \%$ - через 2 года [16]. Остеопоротические переломы регистрируются у $30-$ 50 \% больных, получающих долговременное лечение сГКС. При приеме сГКС в суточной дозе $\geq 5$ мг (в пересчете на преднизолон) риск переломов увеличивается в 1,9 раза по сравнению с общей популяцией, переломов бедра - в 2 раза, позвонков - почти в 2,9 раза. Причем пациенты, принимающие любые дозы сГКС в течение $\geq 3$ мес., относятся к группе высокого риска развития остеопороза и связанных с ним переломов [17]. Среди женщин в постменопаузе, получающих сГКС > 6 мес., при морфометрическом рентгенологическом исследовании переломы позвонка выявляются у $37 \%$ [18].

В мировой практике пролонгированными препаратами ГКС лечат:

1) некоторых страдающих БА психических больных, которые не могут самостоятельно принимать необходимые препараты;

2) асоциальных лиц (наркоманов, алкоголиков) с тяжелой угрожающей жизни БА, отказывающихся правильно лечиться.

Назначая пациентам с БА пролонгированные препараты ГКС, врач ставит их наравне с выше названными категориями больных.

4. Крайне тяжелое, нестабильное течение бронхиальной астмы, не поддающееся другим методам лечения.

Среди наблюдавшихся нами больных стероидозависимой БА таких пациентов - меньшинство. Известно, что до $5 \%$ больных БА не отвечают на тера- пию ГКС - в этих случаях говорят о стероидорезистентной (рефрактерной) БА [11]. Необходимость постоянного приема сГКС может быть обусловлена также генетическими механизмами, приводящими как к повышению экспрессии провоспалительных медиаторов, так и к снижению экспрессии противовоспалительных цитокинов (IL-10, IL-1R- $\alpha$ ). Гомозиготный полиморфизм Gly16 в молекуле $\beta_{2}$-адренорецептора ответственен за снижение реакции на $\beta$-агонисты, выявлена положительная коррелятивная связь этого генетического дефекта с тяжелым течением БА и частотой ее обострений [19].

Продолжается интенсивный поиск методов, направленных на преодоление стероидорезистентности у данной категории больных. Существенно расширил терапевтические возможности в лечении больных с тяжелым течением БА препарат моноклональных анти-IgE-антител - омализумаб. Особенно значима роль Ксолара в лечении пациентов с тяжелой персистирующей БА, не контролируемой приемом высоких доз иГКС в сочетании с длительно действующими $\beta$-агонистами (ДДБА). Омализумаб эффективно снижает количество обострений БА, обращений за экстренной помощью, улучшает показатели проходимости бронхов, снижает потребность в ГКС, способствует достижению контроля над БА [20].

Активно исследуются разные группы цитостатиков с целью снижения стероидозависимости у данной категории больных. Однако ряд обзоров в Кокрановской базе данных за последние годы свидетельствует о недостаточности доказательств в пользу использования метотрексата, азатиоприна и циклоспорина [21-24]. Спаринг-эффекты препаратов золота сопряжены с серьезными побочными эффектами, вследствие чего эти препараты также не могут быть рекомендованы для широкого применения [25]. Обсуждается механизм воздействия на воспаление в бронхах антибиотиков - кларитромицина и телитромицина, однако их стероидозамещающее воздействие нуждается в дополнительных доказательствах [21].

2-й этап. Замещение сГКС комбинацией иГКС и пролонгированных ингаляционных $\beta_{2}$-адреномиметиков.

К получаемому больным лечению (сГКС, обычно в таблетках) добавляют иГКС и пролонгированный симпатомиметик, оптимально - в одном ингаляторе.

Из иГКС наиболее высокой местной противовоспалительной активностью, превосходящей все остальные препараты иГКС по этому параметру в 2 раза, обладает флутиказон. Этот момент принципиально важен, потому что при снятии больного с сГКС назначаются высокие (до 2000 мкг в пересчете на беклометазон) дозы иГКС. Соответственно, для получения аналогичного эффекта применяют дозировку флутиказона в 2 раза ниже, чем остальных иГКС.

3-й этап. Через 2-4 нед. после начала 2-го этапа снижение дозы сГКС.

Снижение дозы следует начинать только после достижения контроля симптомов и восстановления показателей проходимости бронхов, как правило, не 
ранее чем через 2-4 нед. после назначения заместительной терапии.

Схемы снижения дозы сГКС:

1. Больным, принимающим сГКС в дозе > 10 мг в сутки (по преднизолону), дозу снижают на 5 мг на каждом последующем визите; при достижении дозы 10 мг в сутки - на 2,5 мг на каждом последующем визите; а при достижении дозы 5 мг - на 1,25 мг на каждом последующем визите.

2. Больным, принимающим сГКС в дозе $<10$ мг в сутки (по преднизолону), дозу снижают на 2,5 мг на каждом последующем визите; при достижении дозы 5 мг - на 1,25 мг на каждом последующем визите.

3. Пациентам, получающим < 20 мг преднизолона, дозу снижают на 2,5 мг через день.

Схемы снижения дозы являются ориентировочными, темп снижения индивидуальный. Визиты в клинику - каждые 2 нед.

При отсутствии контроля, в зависимости от конкретной ситуации, доза сГКС может быть либо увеличена, либо снижение дозы переносится на следующий визит.

В процессе снижения дозировки сГКС пациент должен ежедневно заполнять дневник самоконтроля, фиксируя количество дневных и ночных симптомов, потребность в $\beta_{2}$-агонистах короткого действия, утреннюю и вечернюю пиковую скорость выдоха (ПСВ) и нежелательные явления. Обязательным условием является мониторирование ПСВ (пикфлоуметрия) с занесением в дневник самоконтроля лучшего утреннего и вечернего показателей. Для выявления обострений БА в дневнике должны отмечаться предупреждающие значения пиковой объемной скорости выдоха (ПОСВ), отражающие снижение показателя > $20 \%$ (среднетяжелое обострение) и $>40 \%$ (тяжелое обострение) от персонального лучшего значения ПОСВ. Персональное лучшее значение ПОСВ может изменяться, в таких случаях необходимо изменять предупреждающие значения.

Любое уменьшение дозы проводится только после визита к врачу, оценки функции внешнего дыхания и при отсутствии клинических и пикфлоуметрических признаков ухудшения состояния больного. В амбулаторной карте должна быть сделана запись, что начата терапия, имеющая целью снижение дозы сГКС, и даны рекомендации для других специалистов, с которыми пациент может контактировать в случае возникновения проблем, о необходимости увеличения дозы сГКС, связанных, например, с необходимостью оперативного вмешательства, травмами, стрессовыми ситуациями и др. Пациенту на руки необходимо выдать памятку, содержащую данные рекомендации. Очередное снижение дозы не проводится, если в течение предшествующих 2 нед. имелся $\geq 1$ из ниже перечисленных признаков:

1) увеличение потребности в быстродействующем

$\beta_{2}$-агонисте $>3$ ингаляций в течение 3 последовательных дней;

2) умеренное обострение БА;
3) снижение объема форсированного выдоха за 1-ю с $\left(\mathrm{OФB}_{1}\right)$ на $\geq 15 \%$ по сравнению с предшествующим визитом.

Пациентам с умеренным обострением должна быть увеличена доза сГКС до 0,5-1 мг / кг преднизолона в сутки (или эквивалент) в течение 7 дней до достижения уровня ПОСВ $\geq 80 \%$ по сравнению с персональным лучшим значением.

Особенно осторожно следует снижать сГКС при достижении дозировки $<1$ таблетки в сутки. У пациентов, получавших высокие суточные дозы (или средние суточные дозы, но в течение длительного времени), могут появиться признаки "синдрома отмены" в виде общей слабости, субфебрилитета и других симптомов - помимо обострения БА. Как правило, с такими явлениями приходится сталкиваться у больных стероидозависимой БА, получающих депонированные инъекционные формы ГКС. В таких случаях пациент продолжает получать 0,5-1 таблетку в сутки по альтернирующей схеме (через день), подключая терапевтические мероприятия, направленные на стимуляцию надпочечников. В этих случаях для полной отмены сГКС требуется более длительное время.

У больных стероидозависимой БА после перевода с таблеток на иГКС нередко рецидивирует ринит, в т. ч. полипозной формы. Хороший эффект дает превентивное назначение назального спрея ГКС.

Необходимо проводить профилактику и лечение глюкокортикоид-индуцированного остеопороза.

К факторам риска остеопороза и обусловленных им переломов относятся следующие факторы [16]:

- низкая костная масса (МПК);

- $\quad$ возраст $\geq 65$ лет;

- предшествующие переломы;

- склонность к падениям;

- наличие остеопороза и / или переломов семейном анамнезе, при минимальной травме у родственников в возрасте $\geq 50$ лет;

- низкий индекс массы тела $(<20$ кг / м²);

- гипогонадизм у мужчин и женщин;

- низкий уровень физической активности и длительная иммобилизация;

- курение;

- недостаточное потребление кальция и витамина D.

K группе высокого риска относятся пациенты > 65 лет, имеющие остеопоротические переломы в анамнезе и склонность к частым падениям, принимающие сГКС (> 20 мг в сутки в пересчете на преднизолон). Если имеется хотя бы 1 из выше перечисленных факторов, то для решения вопроса о назначении лечения не требуется проведения денситометрии. Лечение остеопороза назначается вне зависимости от длительности терапии сГКС.

У остальных пациентов решение о назначении лечения принимается на основании данных рентгеновской абсорбциометрии позвоночника и шейки бедра. Если пациент принимает сГКС > 3 мес., обязательно проводится двухэнергетическая рентгеновская абсорбциометрия, исследование рекомендуется повторять с интервалом в 6-12 мес. на фоне 
лечения сГКС. При снижении МПК на $\geq 1,5 \mathrm{SD}$, по T-критерию, показано назначение антиостеопоротических препаратов [16].

4-й этап. Подбор оптимальной дозы базисной терапии.

После полной отмены сГКС проводится постепенное уменьшение дозы иГКС, не снижая дозу ДДБА.

\section{Заключение}

В настоящее время имеются возможности достижения контроля над стероидозависимой БА, не прибегая к постоянному приему сГКС, а у больных, уже получающих эти препараты, можно существенно снизить их дозу либо отменить полностью. Комплексный подход, основанный на выявлении и устранении причин стероидной зависимости и адекватной базисной терапии с помощью комбинации иГКС и ДДБА, позволяет добиться желаемого результата у подавляющего большинства больных стероидозависимой БА.

Подавляющее большинство больных стероидзависимой БА получают сГКС вследствие ошибок в диагностике и лечении БА; в 9 из 10 случаев у больных стероидозависимой БА можно добиться полной отмены либо существенного снижения дозы сГКС.

При "снятии" больного БА с сГКС наиболее эффективна технология "замещения" комбинацией высоких доз иГКС и ДДБА.

Сочетание этих препаратов в одном ингаляторе (Серетид) повышает эффективность, снижает дозу иГКС, повышает комплайентность.

Предлагаемые рекомендации по ведению пациентов и принципы снижения дозы сГКС основаны на проведенном в России сравнительном рандомизированном многоцентровом открытом исследовании в параллельных группах ГРОЗА (ГоРмональнОЗависимая бронхиальная Астма), целью которого явилось изучение эффективности и безопасности терапии флутиказона пропионатом (Фликсотид) и комбинацией сальметерол / флутиказона пропионат (Серетид) в снижении дозы сГКС у больных стероидозависимой БА. Результатами исследований [26-28] явились следующие выводы:

1. До включения в исследование применение сГКС в течение длительного времени не приводило к достижению контроля над заболеванием, что проявлялось в ежедневном наличии симптомов и связанной с этим потребности в короткодействующих бронходилататорах, ограничении повседневной активности, низких значениях показателей проходимости бронхов, необходимости в обращении за экстренной помощью и госпитализации в связи с обострением БА в течение предшествующего года, наличии осложнений сГКС-терапии у подавляющего числа пациентов.

2. Назначение больным стероидозависимой БА Фликсотида или Серетида в дозированном аэрозольном ингаляторе (ДАИ) в течение 6 мес. позволило снизить дозу сГКС в среднем в 6 раз по сравнению с исходной.
3. К концу 6 мес. терапии у каждого 2-го пациента, получавшего комбинацию сальметерол / флутиказона пропионат, и каждого третьего, получавшего флутиказона пропионат, удалось полностью отменить сГКС.

4. Комбинация сальметерол / флутиказона пропионат достоверно превосходила флутиказона пропионат по влиянию на основной показатель проходимости бронхов $\left(\mathrm{OФB}_{1}\right)$, а также в отношении снижения выраженности ночных приступов БА. На фоне терапии сальметеролом / флутиказона пропионатом достоверно реже развивались среднетяжелые обострения БА.

\section{Литература}

1. Чучалин А.Г. (ред.). Глобальная стратегия лечения и профилактики бронхиальной астмы. М.: Изд. дом "Атмосфера"; 2007.

2. Авдеев С.Н., Карчевская Н.А,. Зубаирова П.А. Синдром Черджа-Стросс как причина рефрактерной бронхиальной астмы. Атмосфера. Пульмонол. и аллергол. 2009; 1: $42-46$.

3. Национальная программа "Бронхиальная астма у детей. Стратегия лечения и профилактика". 3-е изд. М.: Изд. дом "Атмосфера"; 2008.

4. Pearce N., Pekkanen J., Beasley R. How much asthma is really attributable to atopy? Thorax 1999; 54: 268-272.

5. Novak N., Bieber T. Allergic and nonallergic forms of atopic diseases. J. Allergy Clin. Immunol. 2003; 112: 252-262.

6. The ENFUMOSA cross-sectional European multicentre study of the clinical phenotype of chronic severe asthma. Eur. Respir. J. 2003; 22: 470-477

7. Haselkorn T., Borish L., Miller D.P. et al. High prevalence of skin test positivity in severe or difficult-to-treat asthma. J. Asthma 2006; 43: 745-752.

8. Israel E. Aspirin-induced asthma. UpToDate 2000; 8: 3.

9. Fokkens W.J., Lund V.J., Mullol J. et al. European position paper on rhinosinusitis and nasal polyps EPOS. Rhinol. Suppl. 2007; 20: 1.

10. Рязанцев С.В. Современные взгляды на терапию полипозных риносинуситов. Атмосфера. Пульмонол. и аллергол. 2007; 4: 22-26.

11. Proceedings of the ATS workshop on refractory asthma: current understanding, recommendations, and unanswered questions. American Thoracic Society. Am. J. Respir. Crit. Care Med.2000; 162: 2341.

12. NHBLI Guidelines for diagnostic and management of asthma, EPR3. Full Report; 2007.

13. Corren $J$. The link between allergic rhinitis and asthma, otitis media, inusitis, and nasal polyps. Immunol. Allergy Clin. N. Am. 2000; 20: 52-61.

14. Field S.K. Asthma and gastroesophageal reflux: another piece in the puzzle. Chest 2002; 121: 1024-1027.

15. Плешко Р.И., Огородова Л.М, Суходоло И.В. и др. Тяжелая бронхиальная астма и гастроэзофагеальный рефлюкс: морфофункциональные аспекты сопряженности. Пульмонология 2006; 1: 60-63.

16. Баранова И.А. Глюкокортикоидиндуцированный остеопороз. Атмосфера. Пульмонол. и аллергол. 2008; 1: 3-10.

17. van Staa T.P., Leufkens H.G.M., Cooper C. The epidemiology of corticosteroid-induced osteoporosis: a meta-analysis. Osteoporos. Int. 2002; 13: 777-787. 
18. Angeli A., Guglielmi G., Dovio A. et al. High prevalence of asymptomatic vertebral fractures in post-menopausal women receiving chronic glucocorticoid therapy: a crosssectional outpatient study. Bone 2006; 39: 253-259.

19. Chung K.F. The complementary role of glucocorticosteroids and long-acting $\beta_{2}$-adrenergic agonists. Allergy 1998; 53 (42): 7-13.

20. Фассахов Р.С. Ксолар (омализумаб): новые возможности терапии тяжелой бронхиальной астмы. Пульмонология 2007; 4: 100-105.

21. Randhawa I., Klaustermeyer W.B. Oral corticosteroiddependent asthma: a 30-year review. Ann Allergy Asthma Immunol. 2007; 99 (4): 291-302.

22. Corrigan C.J., Shiner R.J., Shakur B.H., Ind P.W. Methotrexate therapy of oral corticosteroid-dependent asthmatics reduces serum immunoglobulins: correlation with clinical response to therapy. Clin. Exp. Allergy 2005; 35 (5): 579-584.

23. Dean T., Dewey A., Bara A. et al. Azathioprine as an oral corticosteroid sparing agent for asthma.Cochrane Database Syst. Rev. 2004; 1: CD003270.

24. Evans D.J., Cullinan P., Geddes D.M. Cyclosporin as an oral corticosteroid sparing agent in stable asthma. Cochrane Database Syst. Rev. 2001; 2: CD002993.

25. Evans D.J., Cullinan P., Geddes D.M. Gold as an oral corticosteroid sparing agent in stable asthma. Cochrane Database Syst. Rev. 2001; 2: CD002985.
26. Фассахов Р.С., Ильина Н.И., Решетникова И.Д. и др. Эффективность и безопасность применения серетида и флутиказона пропионата в снижении дозы системных глюкокортикостероидов у больных гормонозависимой бронхиальной астмой. (Результаты российского многоцентрового исследования "ГРОЗА"). Аллергология 2005; 3: 3-8.

27. Фассахов Р.С., Ильина Н.И., Решетникова И.Д. и др. Гормонозависимая бронхиальная астма: эффективный подход к снижению дозы системных глюкокортикостероидов (результаты российского многоцентрового исследования ГРОЗА). Атмосфера 2005; 2: 56-59.

28. Фассахов Р.С., Решетникова И.Д., Ильина Н.И. и др. Возможности контроля гормонозависимой бронхиальной астмы флутиказона пропионатом и сальметеролом / флутиказона пропионатом: по материалам российского многоцентрового исследования ГРОЗА. Пульмонология 2005; 5: 87-92.

\section{Информация об авторах}

Фассахов Рустэм Салахович - д. м. н., проф., директор ФГУН КНИИЭМ Роспотребнадзора, зав. кафедрой аллергологии и иммунологии гОУ ДПО КГМА Росздрава; тел.: (843) 236-67-21, факс: (843) 236-67-41, еmail: farrus@mail.ru

Решетникова Ирина Дмитриевна - к. м. н., зам. директора по научной и лечебной работе ФГУН КНИИЭМ Роспотребнадзора, доцент кафедры аллергологии и иммунологии ГОУ ДПО КГМА Росздрава; тел.: (843) 236-67-21; факс: (843) 236-67-41, e-mail: reshira@mail.ru

Поступила 09.02.10 (С) Фассахов Р.С., Решетникова И.Д. 2010 удк 616.248-085.234 